\title{
Numerical analysis of a near-room-temperature magnetic cooling system
}

\author{
Mehmet Akif Ezan ${ }^{a}$, Orhan Ekren ${ }^{b, *}$, Cagri Metin ${ }^{a}$, Ahmet Yilanci ${ }^{b}$, \\ Emrah Biyik ${ }^{c}$, Salih Murat Kara ${ }^{d}$ \\ ${ }^{a}$ Department of Mechanical Engineering, Dokuz Eylul University, Izmir, Turkey \\ b Solar Energy Institute, Ege University, Izmir, Turkey \\ ${ }^{c}$ Department of Energy Systems Engineering, Yasar University, Izmir, Turkey \\ d Department of Electrical and Electronics Engineering, Izmir Institute of Technology, Izmir, Turkey
}

\section{A R T I C L E I N F O}

\section{Article history:}

Received 29 June 2016

Received in revised form 12

December 2016

Accepted 23 December 2016

Available online 29 December 2016

\section{Keywords:}

Magnetic cooling

Computational fluid dynamics

ANSYS-FLUENT

User defined functions

\begin{abstract}
A B S T R A C T
In this study, for a near-room-temperature magnetic cooling system, a decoupled multiphysics numerical approach (Magnetism, Fluid Flow, and Heat Transfer) is developed using a commercial CFD solver, ANSYS-FLUENT, as a design tool. User defined functions are incorporated into the software in order to take into account the magnetocaloric effect. Magnetic flux density is assumed to be linear during the magnetization and demagnetization processes. Furthermore, the minimum and maximum magnetic flux densities ( $B_{\min }$ and $B_{\max }$ ) are defined as 0.27 and 0.98 , respectively. Two different sets of analyses are conducted by assuming an insulated cold heat exchanger (CHEX) and by defining an artificial cooling load in the CHEX. As a validation case, experimental work from the literature is reproduced numerically, and the results show that the current methodology is fairly accurate. Moreover, parametric analyses are conducted to investigate the effect of the velocity of heat transfer fluid (HTF) and types of HTF on the performance of the magnetic cooling system. Also, the performance metrics of the magnetic cooling system are investigated with regards to the temperature span of the magnetic cooling unit, and the cooling load. It is concluded that reducing the cycle duration ensures reaching lower temperature values. Similarly, reducing the velocity of the HTF allows reducing the outlet temperature of the HTF. In the current system, the highest temperature spans are obtained numerically as around $6 \mathrm{~K}, 5.2 \mathrm{~K}$ and $4.1 \mathrm{~K}$ for the cycle durations of $4.2 \mathrm{~s}, 6.2 \mathrm{~s}$ and $8.2 \mathrm{~s}$, respectively.
\end{abstract}

(c) 2016 Elsevier Ltd and IIR. All rights reserved.

\section{Analyse numérique d'un système de froid magnétique proche de la température ambiante}

Mots clés : Refroidissement magnétique ; Mécanique numérique des fluides ; ANSYS-FLUENT ; Fonctions définies par l'utilisateur

\footnotetext{
* Corresponding author. Solar Energy Institute, Ege University, Bornova, Izmir 35100, Turkey. Fax: +90 2323886027.

E-mail address: orhanekren@gmail.com (O. Ekren).
}

http://dx.doi.org/10.1016/j.ijrefrig.2016.12.018

0140-7007/@ 2016 Elsevier Ltd and IIR. All rights reserved. 


\begin{tabular}{|c|c|c|c|}
\hline \multicolumn{2}{|c|}{ Nomenclature } & \multicolumn{2}{|c|}{ Subscripts } \\
\hline & & ad & adiabatic \\
\hline \multicolumn{2}{|c|}{ Variables } & & cooling \\
\hline B & magnetic field intensity (Tesla) & in & inlet \\
\hline$B_{j}$ & Brillouin function & out & outlet \\
\hline$c$ & specific heat $\left(\mathrm{J} \mathrm{kg}^{-1} \mathrm{~K}^{-1}\right)$ & $R$ & rejected \\
\hline$g$ & spectroscopic splitting factor & & \\
\hline h & specific enthalpy $\left(\mathrm{J} \mathrm{kg}{ }^{-1}\right)$ & Greek & \\
\hline$J$ & angular momentum & $\eta$ & efficiency (-) \\
\hline$k$ & thermal conductivity $\left(\mathrm{W} \mathrm{m}^{-1} \mathrm{~K}^{-1}\right)$ & $\mu$ & dynamic viscosity $\left(\mathrm{kg} \mathrm{ms}^{-1}\right)$ \\
\hline L & length of the regenerator $(\mathrm{m})$ & $\mu_{\mathrm{B}}$ & Bohr magneton (J Tesla ${ }^{-1}$ ) \\
\hline mce & magnetocaloric effect per unit volume $\left(\mathrm{W} \mathrm{m}^{-3}\right)$ & $\rho$ & density $\left(\mathrm{kg} \mathrm{m}^{-3}\right)$ \\
\hline$M_{M}$ & molar mass $\left(\mathrm{kg} \mathrm{mol}^{-1}\right)$ & $\varphi$ & utilization factor (-) \\
\hline$m$ & mass (kg) & \multirow{2}{*}{\multicolumn{2}{|c|}{ Abbreviations }} \\
\hline$\dot{m}$ & mass flow rate $\left(\mathrm{kg} \mathrm{s}^{-1}\right)$ & & \\
\hline$p$ & pressure $(\mathrm{Pa})$ & AIVIR & 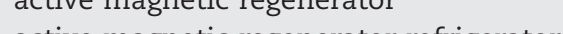 \\
\hline$\dot{Q}$ & rate of heat transfer per unit height $\left(\mathrm{W} \mathrm{m}^{-1}\right)$ & AMRR & active magnetic regenerator refrigerator \\
\hline$R_{u}$ & universal gas constant $\left(\mathrm{J} \mathrm{mol}^{-1} \mathrm{~K}^{-1}\right)$ & CHEX & cold heat exchanger \\
\hline s & specific entropy $\left(\mathrm{J} \mathrm{kg}^{-1} \mathrm{~K}^{-1}\right)$ & COP & coefficient of performance \\
\hline $\mathrm{T}$ & temperature $(\mathrm{K})$ & Gd & gadolinium \\
\hline $\mathrm{t}$ & time $(\mathrm{s})$ & HHEX & hot heat exchanger \\
\hline$u, v$ & $x$ and $y$ components of the velocity $\left(\mathrm{m} \mathrm{s}^{-1}\right)$ & HTF & heat transfer fluid \\
\hline W & width of the regenerator $(\mathrm{m})$ & MCE & magnetocaloric effect \\
\hline$\dot{\mathrm{W}}_{\text {pump }}$ & pump work per unit height ( $\mathrm{W} \mathrm{m}^{-1}$ ) & MFT & mean field theory \\
\hline$w$ & $\begin{array}{l}\text { thickness of gadolinium plate and gap } \\
\text { between the plates }(\mathrm{m})\end{array}$ & UDF & user defined function \\
\hline
\end{tabular}

\section{Introduction}

Reduction of energy usage in heating, ventilation, air conditioning and refrigeration (HVAC\&R) systems has a crucial importance and is attracting more attention from end-users to researchers around the world (Ekren et al., 2011). The main reason for that is heating-cooling systems account for the largest portion of overall energy consumption in domestic and industrial utilization. For example, electricity usage of the HVAC\&R systems is about $40 \%, 31 \%$ and $17 \%$ of the total energy consumption in Europe (Almeida et al., 2003), in USA (Kusiak et al., 2010) and worldwide (Coulomb, 2007), respectively. Furthermore, environmental issues arise from the refrigeration systems due to their harmful refrigerants such as hydro-chlorofluorocarbons and hydrofluorocarbons (Mota-Babiloni et al., 2015). Therefore, efficient and environmentally friendly alternative cooling methods such as magnetic cooling, acoustic cooling, and elasto-caloric cooling technologies are under research and development. However, these systems are not completely ready to replace the conventional vapor compression refrigeration systems (Goetzler et al., 2016; Ožbolt et al., 2014; Qian et al., 2016). Over the past three decades, magnetic cooling has been one of the promising approaches in terms of the efficiency and environmental issues (Engelbrecht et al., 2005; Eriksen et al., 2015). The main reason for that is the fact that, in the past, researchers have assumed that the magnetic cooling method has the potential to achieve efficiencies up to $60 \%$ of Carnot efficiency (Yu et al., 2003; Zimm et al., 1998).

A basic magnetic cooling system consists of a magnet for the magnetization/demagnetization processes, magnetocaloric material, hot and cold side heat exchangers, heat transfer fluid (HTF) and control/auxiliary system equipment. In a magnetic cooling system, different thermodynamic cycles such as Brayton, Ericsson, Carnot, Hybrid Brayton-Ericsson can be followed (Aprea et al., 2015a, 2015b; Kitanovski et al., 2014; Plaznik et al., 2013). In this study, Brayton magnetic cooling cycle has been considered. As represented in Fig. 1, the cycle mainly consists of four processes: adiabatic magnetization (A-B), isomagnetic heat removal $(\mathrm{B}-\mathrm{C})$, adiabatic demagnetization ( $\mathrm{C}$ $D)$ and isomagnetic heat absorption (D-A). During the magnetization stage, increasing the magnetic field results in an increase in temperature of the magnetocaloric material. On the other hand, during the demagnetization stage, decreasing the magnetic field results in a reduction in temperature of the magnetocaloric material because of a physical effect known as magnetocaloric effect (MCE). The magnetization and demagnetization processes can be viewed as analogous to compression and expansion in a vapor compression cycle.

Research on magnetic cooling resulted in some prototypes around the world. Kitanovski et al. (2015) summarized some of these prototypes up to the year of 2015 in their book. However, currently, commercial systems of magnetic refrigeration are very limited. Several issues are arising related to the design of the magnetocaloric bed, heat transfer mechanism between the bed and the HTF (Kitanovski et al., 2015).

As explained above, magnetocaloric effect (MCE) is the underlying phenomenon in magnetic cooling theory. Weiss and 


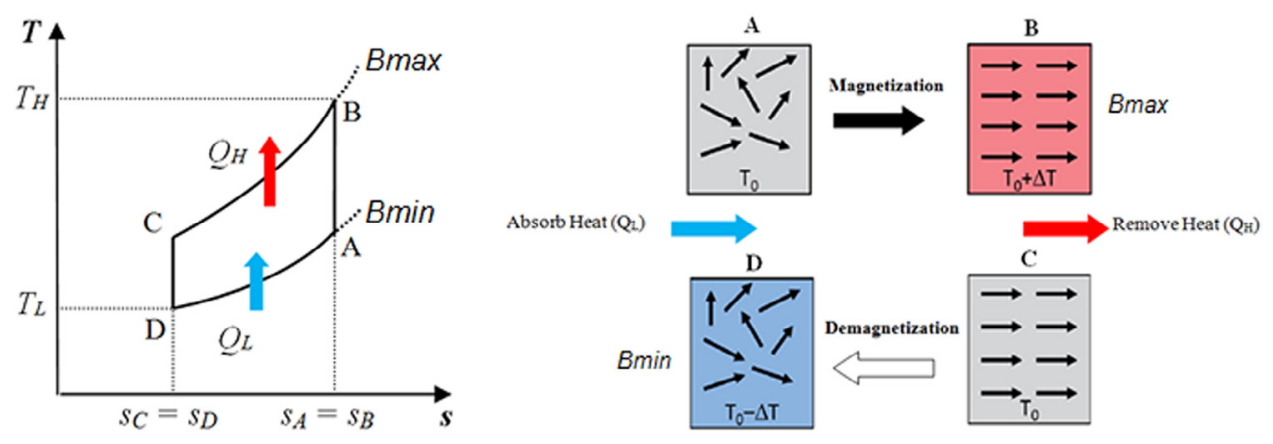

Fig. 1 - T-s diagram for the Brayton cycle with flow diagram of magnetic cooling cycle.

Piccard (1918) discovered the MCE in the early 1900s (Smith, 2013). At first, the MCE technique was used to reach temperatures below liquid helium. In 1933, Giauque and MacDougall (Giauque and MacDougall, 1933) established for the first time a magnetic cooling system. They have used paramagnetic salts and obtained a temperature span of $250 \mathrm{mK}$. The research on the near room temperature magnetic refrigeration applications was started with the first magnetic cooler prototype developed by Brown (1976).

In the literature, research on magnetic cooling systems can be classified into two groups as numerical and experimental studies. In this paper, only numerical studies have been summarized since the authors propose a theoretical approach using a decoupled multiphysics numerical model (Magnetism, Fluid Flow and Heat Transfer) as a design tool of an active magnetic cooling system. Tishin (1990) evaluated the magnetic entropy variations of materials with different Debye temperatures (Gd, Tb, Dy, Ho, Er, Ym, De, Ni, and Co) under a wide range of magnetic flux densities, and compared the predictions with the experimental data. Tishin applied Mean-Field-Theory (MFT) to predict the thermal properties, and the results showed that the proposed method was quite accurate. Siddikov et al. (2005) developed a 1D transient numerical model of the active magnetic regenerator (AMR) with packed bed magnetic material. Adiabatic temperature variation and the specific heat of Gd were obtained as an approximate function regarding the temperature of the material and the magnetic field intensity. The temperature variations inside the bed were revealed during different periods of the system. Sarlah et al. (2006) designed a porous honeycomb regenerator and numerically investigated the arrangements of the various magnetic sheets on the temperature span. Petersen et al. (2008a) compared 1D and 2DAMR models. It was concluded that the $1 \mathrm{D}$ model was sufficient only when the temperature gradients were relatively small inside the AMR. Petersen et al. (2008b) implemented a 2DAMR model in the commercial CFD solver COMSOL Multiphysics. They have applied three tests to check the validity of the numerical scheme: (i) the conservation of energy, (ii) independence of the results from the initial conditions and (iii) the influence of the grid size and time step size. Nielsen et al. (2009) extended their previous code (Petersen et al., 2008b) to include the heat transfer from the lateral surfaces of the AMR to the surroundings. Comparative results revealed that the proposed $2.5 \mathrm{D}$ model showed better agreement with the experimental data regarding the temperature span between the hot and cold end of the AMR. Sarlah and Poredos
(2010) introduced a dimensionless model to determine the heat transfer coefficient of the regenerator and the operation of the AMR refrigerator (AMRR). According to the sensitivity analysis, $10 \%$ variation in the heat transfer coefficient yielded nearly $4 \%$ difference in the temperature span of the AMRR. They indicated that the proper model should be used to decrease the uncertainty arising from the heat transfer coefficient of the fluid. Roudaut et al. (2011) developed a 1D transient numerical code for an AMR. The mean field theory was used to evaluate the magnetocaloric properties of Gd. The influence of the design and working parameters of the AMR were represented in terms of the temperature span and the cooling power. You et al. (2016) proposed a multi-layer AMR consisting of pure $\mathrm{Gd}$ and $\mathrm{Gd}_{0.73} \mathrm{~Tb}_{0.27}$ to improve the temperature span and the cooling performance of the refrigeration system. They have developed an inhouse code in which multi-physical mechanisms are considered. Numerical results showed that the proposed multi-layer AMR unit can yield higher temperature spans with improved COP in comparison to the systems with pure Gd. Chen et al. (2014) experimentally and numerically investigated reciprocating AMR system with the micro channel. The ANSYS-FLUENT software was used to simulate transient heat transfer of the AMR. Instead of calculating the adiabatic temperature change of the material as a function of temperature and magnetic flux density, they defined a constant source term as a function of temperature variation. Aprea et al. (2015a) numerically investigated the thermal and hydraulic behavior of an AMR. They have implemented a source term into energy equation to consider the MCE. In this model, since they have defined a ramp increment or reduction for the magnetic field, it is convenient to define a source term as a function of temperature for a specific magnetic field variation. To do so, they fitted a curve for the MCE as a function of the Gd temperature.

In another study, Aprea et al. (2015b) presented a new refrigeration concept named as GeoThermag. This concept was a combination of magnetic refrigeration technology with a lowtemperature geothermal energy system. In this application, a magnetic refrigerator was connected to a geothermal probe, and $20 \mathrm{~kg}$ of gadolinium was used. They found that the new refrigeration concept GeoThermag system was capable of providing cold water for feeding a radiating panel and delivering $190 \mathrm{~W}$ cooling capacity with a COP of 2.20. Aprea et al. (2016) reported useful results of another new experimental study conducted on a Rotary Permanent Magnet Magnetic Refrigerator (RPMMR) which was named 8Mag. This system had Halbach 
array configuration and produced a peak magnetic flux density of $1.25 \mathrm{~T}$. In the experimental rig, eight radial placed regenerators which were filled with gadolinium spheres with a total refrigerant mass of $1.20 \mathrm{~kg}$ were used. Furthermore, demineralized water was used as regenerator fluid. The fluid was distributed by a rotary valve positioned within the magnetic system; on the other hand, circulation of the fluid was obtained via commercial rotary vane type pump. The results showed a maximum temperature span of $11.9^{\circ} \mathrm{C}$ (at zero cooling load and $296 \mathrm{~K}$ ) and a maximum COP of 2.5 (at $200 \mathrm{~W}$ thermal load).

Kamran et al. (2016), on the other hand, proposed a novel AMR bed which is designed as a microchannel heat exchanger. To simulate the conjugated conduction and convection heat transfer problem within the bed, they have used the ANSYS-FLUENT software. They have proposed piece-wise polynomial functions to define the MCE for a particular magnetic field variation of $\Delta B=0.8$ Tesla.

As stated by Kamran et al. (2016), majority of the numerical studies related to the magnetic cooling technologies were conducted by reducing the problem into $1 \mathrm{D}$. To understand the flow and thermal behaviors of the regenerators, more advanced computational methods could be used to simulate complex geometries or to implement mature technologies, such as microchannel heat exchangers, in the design of regenerators which are utilized in the magnetic cooling systems (Kamran et al., 2016). The main advantage of using a commercial CFD solver is that, rather than reducing the flow field into a $1 D$ model, 2D or 3D Navier-Stokes equations coupled with the energy equation are resolved more easily. In the literature, one of the most widely used CFD software to design heat exchangers is ANSYS-FLUENT (Bhutta et al., 2012). However, so far, there is no embedded tool in that software to simulate the magnetic cooling. In the current study, a numerical model is developed in ANSYS-FLUENT software to investigate the design and working parameters of a near-room-temperature magnetocaloric cooling system. Similar to the previous models in the literature, a decoupled approach is followed, in which, rather than resolving the magnetic field equations, the magnetic effect is implemented in the energy equation as a source term. In the literature, researchers (Chen et al., 2014; Kamran et al., 2016) have already used ANSYS-FLUENT to simulate the magnetic cooling systems. However, rather than defining the magnetocaloric source term in the energy equation as function of magnetic field intensity and the temperature of the Gd, they have either reduced the source term into temperature variation or simplified the multi-variable source term, mce(B, $\mathrm{T})$, into a single variable source, such as mce(T), by using fitted curve equations for a single magnetic field variation interval. In this work, a parallel user defined function (UDF) is coded to implement the MFT into the software and provide an accelerated solution procedure. To the best of our knowledge, it is the first time that the MFT is implemented into the ANSYSFLUENT as multi-variable source term which covers both the temperature and magnetic field variations of the magnetocaloric material. The validity of the proposed scheme is proven by reproducing the experimental work of Bahl et al. (2008). Comparative results with the experimental data reveal that the current approach predicts the magnetic cooling effect fairly accurately. Further parametric analyses are conducted to investigate the effect of working and design

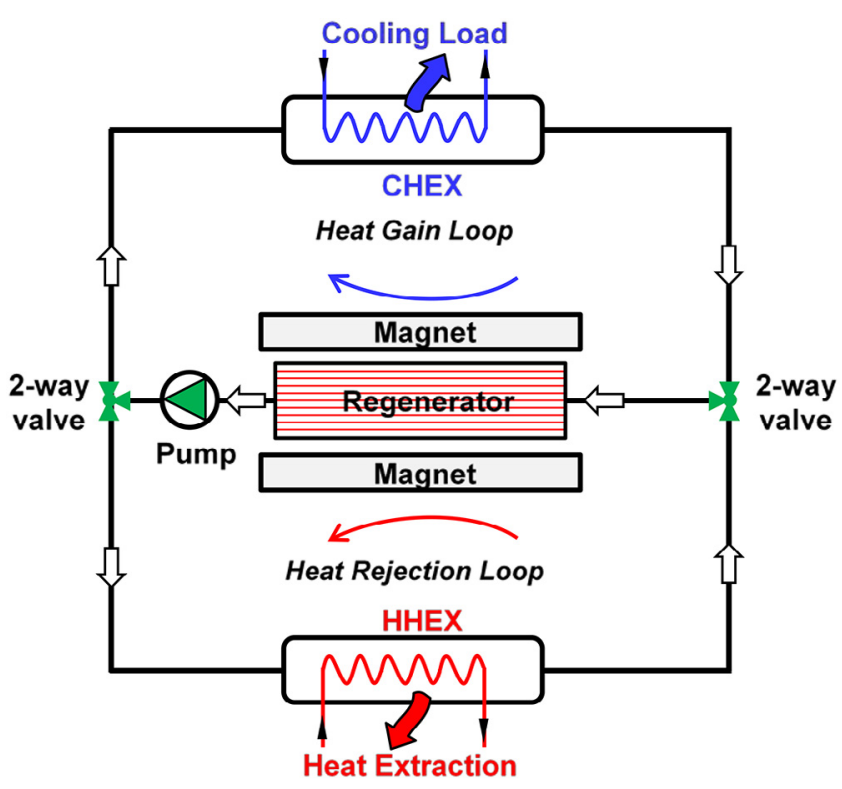

Fig. 2 - Schematic of the near room-temperature magnetic cooling system.

parameters on the performance of the proposed magnetocaloric cooling unit.

\section{Numerical modeling of magnetic cooling unit}

\subsection{Description of the system}

The heat transfer mechanism in the Gd bed is investigated for some selected working parameters. The proposed near-roomtemperature magnetic cooling system is shown in Fig. 2. The system consists of a magnetic cooling unit (Gd bed or regenerator), magnets, heat exchangers, pump, pipes, valves, and connections. A permanent magnet pair generates a magnetic field. Magnetic field generation part is represented in the Appendix A. HTF is distributed into each pipe by solenoid valves. The Gd bed has a linear reciprocating motion provided by a motor for magnetization/demagnetization processes.

\subsection{Problem definition and boundary conditions}

In the current study, instead of modeling the combined system that is defined in Fig. 2, only the magnetic cooling unit (or the regenerator) is considered. Fig. 3a,b illustrates the reduced twodimensional computational domain. The authors have proposed to treat the Gd bed as a parallel flow heat exchanger. There is a total of $50 \mathrm{Gd}$ plates with a thickness of $1 \mathrm{~mm}$. HTF flows through the $1 \mathrm{~mm}$ gap between each plate. The length and the width of the unit are $L=200 \mathrm{~mm}$ and $W=100 \mathrm{~mm}$, respectively. Since the flow field and the temperature distributions are symmetrical throughout the bed width, the computational domain is reduced into one module as shown in Fig. 3b. The simplified computational domain includes two half Gd plates and a flow domain. Preliminary analyses proved that simplifying the model into one-fiftieth considerably decreases the 


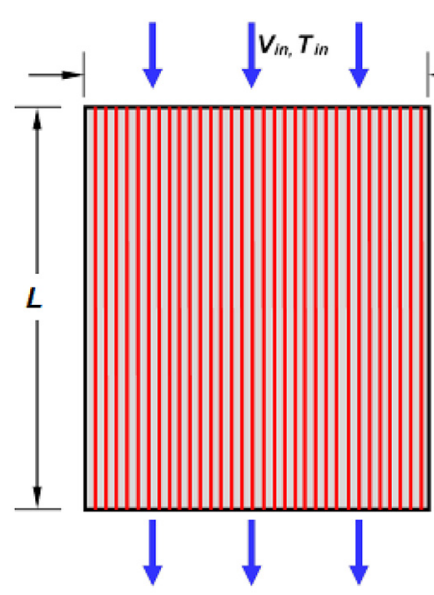

(a) Full unit (b) Computational Domain

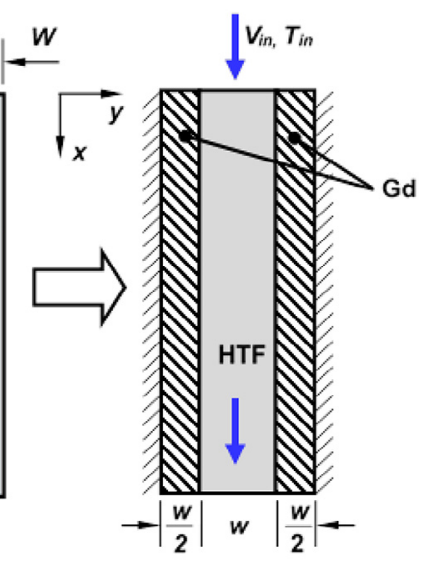

Fig. 3 - Magnetic cooling unit and computational domain.

computational time with negligible effect on the accuracy of the predictions. As indicated in the introduction section in detail, the magnetocaloric cooling unit consists of four stages of the Brayton cycle. In the numerical model, to simulate each of these steps, the boundary conditions should have a transient nature. In Fig. 4, the time-wise variation of the magnetic flux density and the velocity of the HTF are given. Magnetic flux density is assumed to be linear during the magnetization and demagnetization processes. This assumption is commonly used for simplification of the magnetic flux density variation, and is acceptable to define the magnetic field effect (Bahl et al., 2008). In the magnetization process (a), the magnetic-flux density is linearly increased from $B_{\min }$ to $B_{\max }$ and during this period the fluid within the unit is stagnant. HTF flows between the Gd plates in the second period (b) to release the excessive heat from the Gd plates. In this stage, the inlet temperature of the HTF $\left(T_{\text {in }}\right)$ is at the ambient conditions. In the demagnetization process (c), the magnetic-flux density is linearly reduced from $B_{\max }$ to $B_{\min }$ and, during this period there is no fluid flow. In the last process of the cooling cycle $(d)$, the fluid flow becomes activated, and Gd absorbs heat from the HTF. The minimum and maximum magnetic flux densities $\left(B_{\min }\right.$ and $B_{\max }$ ) are defined as 0.27 and 0.98 , respectively (see Appendix A). The durations for the magnetization and demagnetization are kept constant for all analyses as $\Delta t_{\text {mag }}=\Delta t_{\text {de-mag }}=0.1 \mathrm{~s}$. Two different sets of analyses are conducted by assuming an insulated cold heat exchanger (CHEX) and defining an artificial cooling load in the CHEX. In the loaded case, it is assumed that the HTF leaves the CHEX with a

\begin{tabular}{|c|c|c|c|c|}
\hline \multirow[t]{2}{*}{ Case } & \multirow[t]{2}{*}{ Utilization } & $t_{\text {cycle }}=4.2 \mathrm{~s}$ & $t_{\text {cycle }}=6.2 \mathrm{~s}$ & $t_{\text {cycle }}=8.2 \mathrm{~s}$ \\
\hline & & $\begin{array}{c}\text { Inlet } \\
\text { velocity, } \\
\mathrm{V}_{\text {in }}\left(\mathrm{m} \mathrm{s}^{-1}\right)\end{array}$ & $\begin{array}{c}\text { Inlet } \\
\text { velocity, } \\
V_{\text {in }}\left(\mathrm{m} \mathrm{s}^{-1}\right)\end{array}$ & $\begin{array}{c}\text { Inlet } \\
\text { velocity, } \\
\mathrm{V}_{\text {in }}\left(\mathrm{m} \mathrm{s}^{-1}\right)\end{array}$ \\
\hline 0 & 0.0032 & 0.00004676 & 3.11733E-05 & 0.00002338 \\
\hline 1 & 0.0317 & 0.0004676 & 0.000311733 & 0.0002338 \\
\hline 2 & 0.0633 & 0.0009352 & 0.000623467 & 0.0004676 \\
\hline 3 & 0.1266 & 0.0018704 & 0.001246933 & 0.0009352 \\
\hline 4 & 0.2532 & 0.0037408 & 0.002493867 & 0.0018704 \\
\hline 5 & 0.5065 & 0.0074816 & 0.004987733 & 0.0037408 \\
\hline 6 & 1.0129 & 0.0149632 & 0.009975467 & 0.0074816 \\
\hline
\end{tabular}

temperature increment of $1 \mathrm{~K}$. In practical engineering applications, current definition corresponds to a transient cooling load in CHEX by monitoring the temperature at the outlet section of CHEX.

Numerical analyses are conducted at various mass-flow rates, for different types of HTFs and different cycle durations, to assess the effect of each parameter on the performance of the magnetic cooling unit. In the literature, the common approach to evaluate performance is to obtain the results as a function of the dimensionless parameter called utilization factor. Here the utilization factor is defined as

$\varphi=\frac{\dot{m}_{\mathrm{HTF}} c_{\mathrm{HTF}} \mathrm{t}_{\text {flow }}}{m_{\mathrm{Gd}} \mathrm{c}_{\mathrm{Gd}}}$

Where $t_{\text {flow }}=\Delta t_{\text {flow, } 1}+\Delta t_{\text {flow, 2. Water, ethylene-glycol and }}$ ethanol-water mixture (10\% water by volume) are used as the HTF. Moreover, the cycle durations are selected as $4.2 \mathrm{~s}, 6.2 \mathrm{~s}$ and $8.2 \mathrm{~s}$. A total of 56 analyses are conducted and the parameters that are considered in the study are given in Tables 1 and 2.

\subsection{Solution method}

The magnetic cooling unit is numerically investigated by using a commercial finite volume solver, ANSYS-FLUENT. In the mathematical model, the following assumptions are considered:

- The fluid is incompressible and Newtonian.

- The effective heat transfer mechanisms inside the unit are convection and conduction. The influence of radiation is neglected.

- Flow is laminar.

- The thermo-physical properties of the fluid are constant.

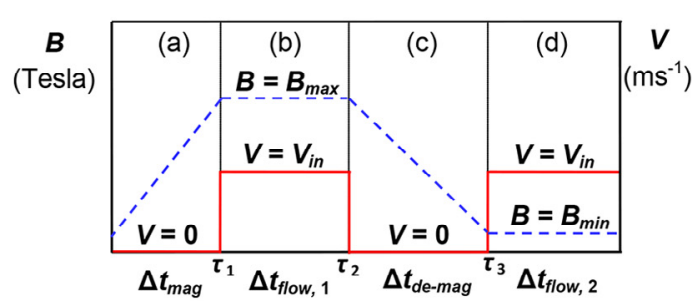

(a) Magnetization

( $B$ increases linearly, $V=0$ )

(b) Heat rejection

$\left(B=B_{\max }, V=V_{\text {in }}\right)$

(c) De-Magnetization

(B decreases linearly, $V=0$ )

(d) Heat gain

$\left(B=B_{\min }, V=V_{\text {in }}\right)$

Fig. 4 - Boundary conditions for magnetization/demagnetization and fluid flow. 


\begin{tabular}{|c|c|c|c|c|}
\hline \multirow[t]{2}{*}{ Case } & \multirow[t]{2}{*}{ Utilization } & Water & $\begin{array}{l}\text { Ethylene- } \\
\text { Glycol }\end{array}$ & $\begin{array}{c}\text { Ethanol-Water } \\
\text { Mixture }\end{array}$ \\
\hline & & $\begin{array}{l}\text { Velocity } \\
\left(\mathrm{m} \mathrm{s}^{-1}\right)\end{array}$ & $\begin{array}{c}\text { Inlet } \\
\text { velocity, } \\
\mathrm{V}_{\text {in }}\left(\mathrm{m} \mathrm{s}^{-1}\right)\end{array}$ & $\begin{array}{c}\text { Inlet } \\
\text { velocity, } \\
\mathrm{V}_{\text {in }}\left(\mathrm{m} \mathrm{s}^{-1}\right)\end{array}$ \\
\hline 0 & 0.0032 & 0.00004676 & $7.27632 \mathrm{E}-05$ & 4.59534E-05 \\
\hline 1 & 0.0317 & 0.0004676 & 0.000727632 & 0.000459534 \\
\hline 2 & 0.0633 & 0.0009352 & 0.001455265 & 0.000919068 \\
\hline 3 & 0.1266 & 0.0018704 & 0.002910529 & 0.001838136 \\
\hline 4 & 0.2532 & 0.0037408 & 0.005821059 & 0.003676271 \\
\hline 5 & 0.5065 & 0.0074816 & 0.011642118 & 0.007352542 \\
\hline 6 & 1.0129 & 0.0149632 & 0.023284236 & 0.014705085 \\
\hline
\end{tabular}

For the fluid domain, the two-dimensional governing equations could be reduced as below.

Continuity:

$\frac{\partial u}{\partial x}+\frac{\partial v}{\partial y}=0$

x-momentum:

$\frac{\partial}{\partial t}(\rho u)+\frac{\partial}{\partial x}(\rho u u)+\frac{\partial}{\partial y}(\rho v u)=-\frac{\partial p}{\partial x}+\frac{\partial}{\partial x}\left[\frac{\partial}{\partial x}(\mu u)\right]+\frac{\partial}{\partial y}\left[\frac{\partial}{\partial y}(\mu u)\right]$

y-momentum:

$\frac{\partial}{\partial t}(\rho v)+\frac{\partial}{\partial x}(\rho u v)+\frac{\partial}{\partial y}(\rho v v)=-\frac{\partial p}{\partial y}+\frac{\partial}{\partial x}\left[\frac{\partial}{\partial x}(\mu v)\right]+\frac{\partial}{\partial y}\left[\frac{\partial}{\partial y}(\mu v)\right]$

Energy:

$\frac{\partial}{\partial t}(\rho c T)+\frac{\partial}{\partial x}(\rho u c T)+\frac{\partial}{\partial y}(\rho v c T)=\frac{\partial}{\partial x}\left[\frac{\partial}{\partial x}(k T)\right]+\frac{\partial}{\partial y}\left[\frac{\partial}{\partial y}(k T)\right]$

For the solid domain, the following energy equation is resolved,

$\frac{\partial}{\partial t}(\rho c T)=\frac{\partial}{\partial x}\left[\frac{\partial}{\partial x}(k T)\right]+\frac{\partial}{\partial y}\left[\frac{\partial}{\partial y}(k T)\right]+$ mce.

Continuity and momentum equations are resolved with the Semi-Implicit Method for Pressure Linked Equations (SIMPLE) algorithm for the fluid domain. The second-order upwind scheme is implemented for discretization of the convective terms in the momentum and energy equations. The last term of the energy equation for the solid domain (Eq. 6) represents the magnetocaloric effect (MCE). The magnetocaloric effect for the Gd samples can be calculated analytically by following the works of Tishin (1990) and De Oliveira and von Ranke (2010). MCE term is incorporated into energy equation as a volumetric heat source $\left(\mathrm{Wm}^{-3}\right)$, and defined as a function of the cell temperature and the magnetic flux density acting on the Gd plates:

mce $=\rho c\left(\frac{\partial T}{\partial B}\right)_{S} \frac{\partial B}{\partial t}$.
The last term in the Eq. (7), ( $\partial \mathrm{B} / \partial \mathrm{t})$, indicates the time-wise variation of the magnetic flux intensity and it is an input for the current transient problem (see Fig. 4). On the other hand, $(\partial T / \partial \mathrm{B})_{S}$ is known as the adiabatic temperature change. The procedure of the calculating the adiabatic temperature change and the specific heat of the magnetic material are represented in the Appendix B. A user-defined-function (UDF) procedure is developed in $\mathrm{C}$ programming language to calculate the mce term in the energy equation and also the specific heat of the Gd. The flow diagram of the script and the detailed explanation of the algorithm are also given in Appendix B.

In the numerical analyses, it is assumed that the fluid is initially at rest $(u=v=0)$ and the solid/fluid domains are at $T_{\text {initial }}=300 \mathrm{~K}$. The computational domain is divided into 40,000 structured control volumes and the time-step size was defined as $\Delta t=0.01 \mathrm{~s}$. The convergence criteria for each governing equation are set to be $10^{-4}$. The UDF code is optimized for parallel computing to decrease the computational cost for each parametric run.

\subsection{Validation of the solution method}

Experimental study on the magnetic cooling unit (Gd bed or AMR) of Bahl et al. (2008) is reproduced to prove the accuracy of the current method implemented into ANSYS-FLUENT software. In the design of Bahl et al. (2008), the magnetic cooling unit consists of $13 \mathrm{Gd}$ plates with $0.9 \mathrm{~mm}$ thickness. The distance between each Gd plate is $0.8 \mathrm{~mm}$, and the length of each plate is $40 \mathrm{~mm}$ through the flow direction. There are $20 \mathrm{~mm}$ long plastic guides, as flow straightener, on each side of the Gd plates to provide laminar flow in the bed. Thermo-physical properties of the materials, Gd, thermoplastic and water, are defined according to the reference study and also Bjørk et al., (2010). The Gd bed is placed inside a piston-cylinder assembly, and the stroke of the piston is given as $50 \%$ of the length of the Gd plates. Moving mesh scheme is defined to simulate piston movement in ANSYSFLUENT software. The magnetic flux density (B) is varied from 0.3 to 1.3 Tesla, and the temperature span is compared with the experimental and numerical results in the reference study. In Fig. 5, current predictions are compared with the results of the

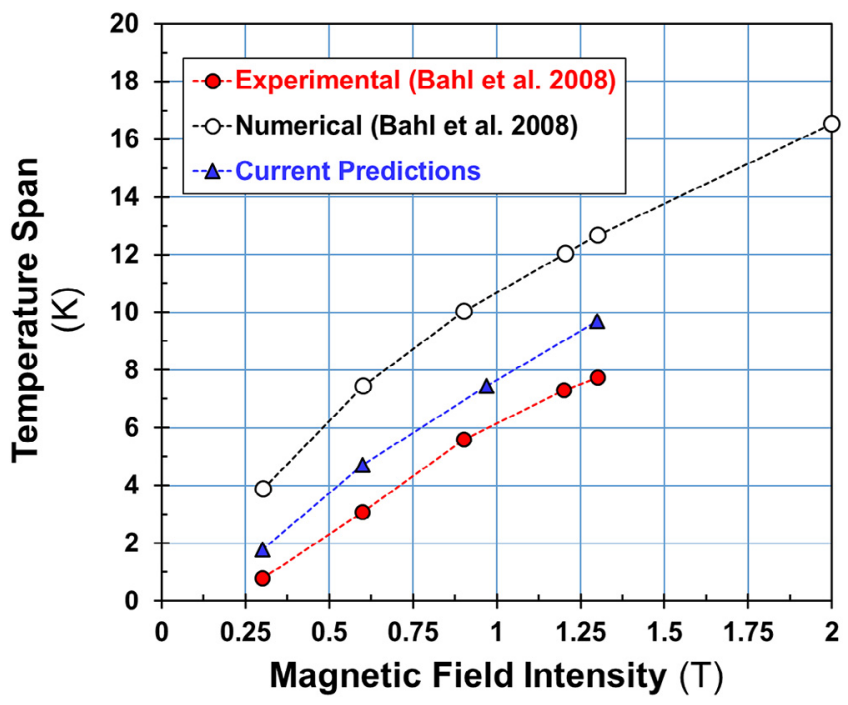

Fig. 5 - Comparative results for temperature span. 
reference work. Even though the current results appear to be over predicting the experimental data, considering the discrepancy between the numerical and experimental results of Bahl et al. (2008), it is clear that the current model developed in ANSYS-FLUENT has better accuracy regarding the temperature span. In the reference paper, Bahl et al. (2008) implemented some representative correlations for the magnetocaloric effect and the heat transfer between the Gd and the HTF. In the current model, however, the magnetocaloric effect is directly calculated from the mean-field-theory, and the piston motion is simulated as a moving mesh by resolving 2D Navier-Stokes equations. It can be concluded that implementation of a more comprehensive solution strategy leads to increase the accuracy of the numerical model.

\section{Results and discussions}

\subsection{Performance metrics of the magnetic cooling system}

The performance of the magnetic cooling system is investigated regarding the temperature span of the magnetic cooling unit and the cooling load. The temperature span is defined as the difference between the initial temperature and the cycle average outlet temperature of the HTF during the heat gain process,

$\Delta T(t)=T_{\text {initial }}-\frac{1}{\Delta t_{\text {flow }, 2} w} \int_{\tau_{3}}^{t_{\text {cycle }}} \int_{w / 2}^{w+w / 2} T(y, t) d y d t$.

The cycle average cooling load is calculated according to the temperature difference of HTF between the inlet and outlet sections of the regenerator during the heat gain process,

$\dot{Q}_{C}=\frac{1}{\Delta t_{\text {flow }, 2}} \int_{\tau_{3}}^{t_{\text {tycle }}} \dot{m}(t) c_{\text {HTF }}\left[T_{\text {in }}(t)-T_{\text {out }}(t)\right] d t$

where the limits of the integral are defined in Fig. 4. Since the analyses are carried out for 2D domain, the cooling load is represented per unit height of the $\mathrm{Gd}$ plate $\left(\mathrm{W} \mathrm{m}^{-1}\right)$. COP of a cycle is defined by following the recent studies of Lionte et al. (2015) and Lozano et al. (2016) as

$\mathrm{COP}=\frac{\dot{\mathrm{Q}}_{\mathrm{C}}}{\dot{\mathrm{Q}}_{\mathrm{R}}-\dot{\mathrm{Q}}_{\mathrm{C}}+\dot{\mathrm{W}}_{\text {pump }}}$

where $\dot{Q}_{C}$ is the cooling load (Eq. (9)) and $\dot{Q}_{R}$ is the rejected heat from Gd. The pumping power, $\dot{\mathrm{W}}_{\text {pump }}$, is evaluated by the following well-known expression,

$\dot{\mathrm{W}}_{\text {pump }}=\frac{\dot{\mathrm{m}}_{\mathrm{HTF}} \Delta p}{\rho_{\mathrm{HTF}} \eta_{\text {pump }}}$

where the pressure drop, $\Delta p$, is the output of the CFD analyses and the pump efficiency, $\eta_{\text {pump }}$ is assumed to be 0.8 as in Lionte et al. (2015) and Kawanami et al. (2011). Average $\dot{Q}_{R}$ can be calculated from the internal energy variation of the $\mathrm{Gd}$ as follows,

$\dot{Q}_{R}=\frac{1}{\Delta t_{f l o w, 1}} \int_{\tau_{1}}^{\tau_{2}} m_{G d} \frac{[h(t)-h(t-\Delta t)]}{\Delta t} d t$ where $h$ is the volume averaged specific enthalpy of the solid domain, and $\Delta t$ is the time step size.

\subsection{Effect of flow time}

In the magnetic cooling unit, three different cycle durations are investigated as $t_{\text {cycle }}=4.2 \mathrm{~s}, 6.2 \mathrm{~s}$ and $8.2 \mathrm{~s}$. Two discrete sets of analyses are conducted with and without a cooling load at the CHEX. In Fig. 6, the time-wise variation of the temperature span for various cycle durations in unloaded CHEX situation is shown. It is clear that increasing the cycle duration reduces the maximum value of temperature span. The highest temperature spans are obtained as around $6 \mathrm{~K}, 5.2 \mathrm{~K}$ and $4.1 \mathrm{~K}$ for cycle durations of $4.2 \mathrm{~s}, 6.2 \mathrm{~s}$ and $8.2 \mathrm{~s}$, respectively. The number of cycles to reach the steady-state condition and the fluctuations in the cycle averaged temperature span values are also reduced with increasing the cycle duration. As a result, the smaller cycle durations provide the lower temperature values, which is consistent with the numerical and experimental findings of Bahl et al. (2008). In Fig. 7, the steady-state temperature spans are given as a function of the utilization factor. For each cycle duration, the highest temperature span is observed for Case \#1, which corresponds $\varphi=0.0317$. Beyond this value, temperature span reduces by increasing the utilization factor. It is also interesting that beyond a certain value of the utilization factor, the curves overlap and the variations become almost independent of the change in cycle duration. As seen in Table 1, the utilization factor is varied by changing the velocity of HTF from 0.00004676 to $0.0149632 \mathrm{~m} \mathrm{~s}^{-1}$. Since the time of heat transfer between the fluid and the Gd increases as reducing the speed of the HTF, the outlet temperature of the HTF approaches to the Gd temperature for slow fluid velocity values. The highest outlet temperature of HTF (smaller temperature span) is obtained at the maximum fluid velocity.

In the next part of the study, a predefined temperature increment is defined at the CHEX to simulate the loaded situation. Fig. 8 shows the time-wise variations of cooling loads for each case and cycle duration. The cooling load has an initial transient region, which corresponds to 10-15 cycles depending on the utilization factor. In this region, the cooling load suddenly increases to the maxima and then gradually approaches to the steady-state value. Cooling load is defined regarding the mass flow rate at the outlet of the regenerator (Eq. (8)). That is, the overshoots may arise due to the difference between the mean velocity values at the inlet and outlet sections. It is clear that the maximum discrepancy is observed in Case \#6 for all cycle durations and the difference is less than $5 \%$. The highest cooling loads are obtained for the maximum HTF velocities. As the velocity reduces, the cooling load approaches toward zero.

In Fig. 9 the relationship between the temperature span and the utilization is represented under a steady-state condition. It is interesting to note that the variations resemble the ones in the unloaded situation (Fig. 7) for the utilization factor values less than 0.2. Beyond this value, the gap between the loaded and unloaded cases increases regarding the temperature span. For instance, at $\varphi=1.0129$ the temperature span reduces almost one third compared to the unloaded situation.

Fig. 10 combines the previous two graphs and represents the variations of cooling load as a function of temperature span for each cycle duration. The highest cooling loads could be 


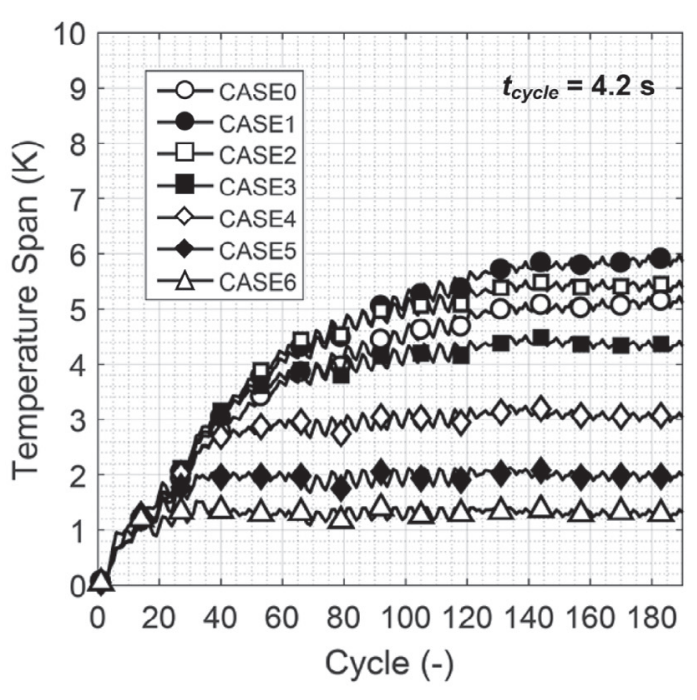

(a) $t_{\text {cycle }}=4.2 \mathrm{~s}$

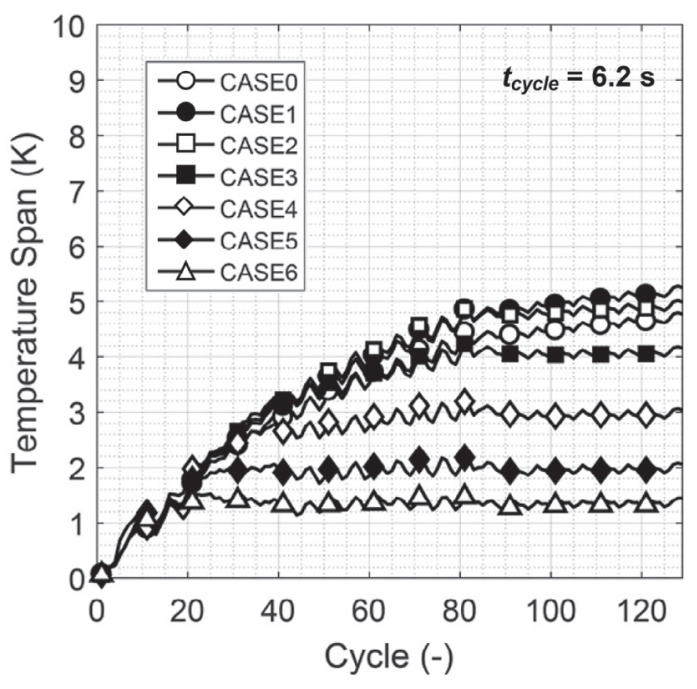

(b) $t_{\text {cycle }}=6.2 \mathrm{~s}$

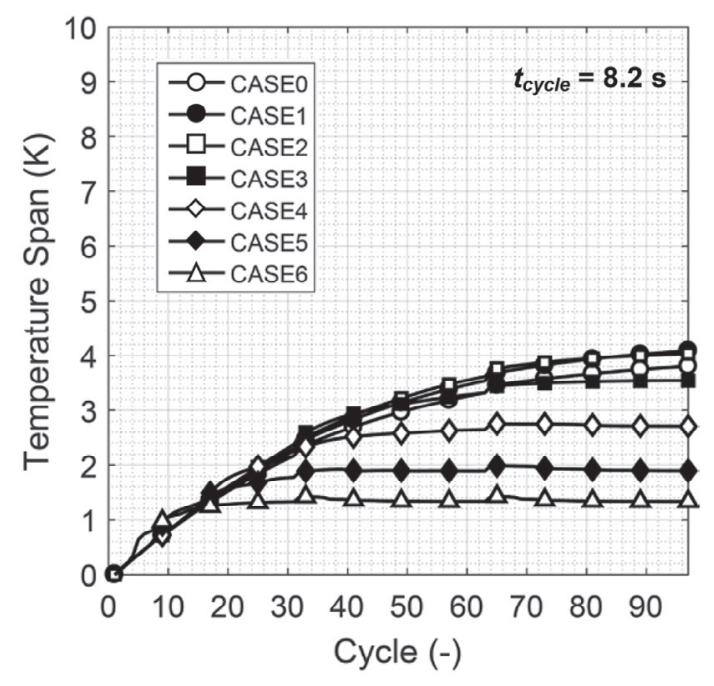

(c) $t_{\text {cycle }}=8.2 \mathrm{~s}$

Fig. 6 - Time evaluation of temperature span for different cycle durations in unloaded CHEX case.

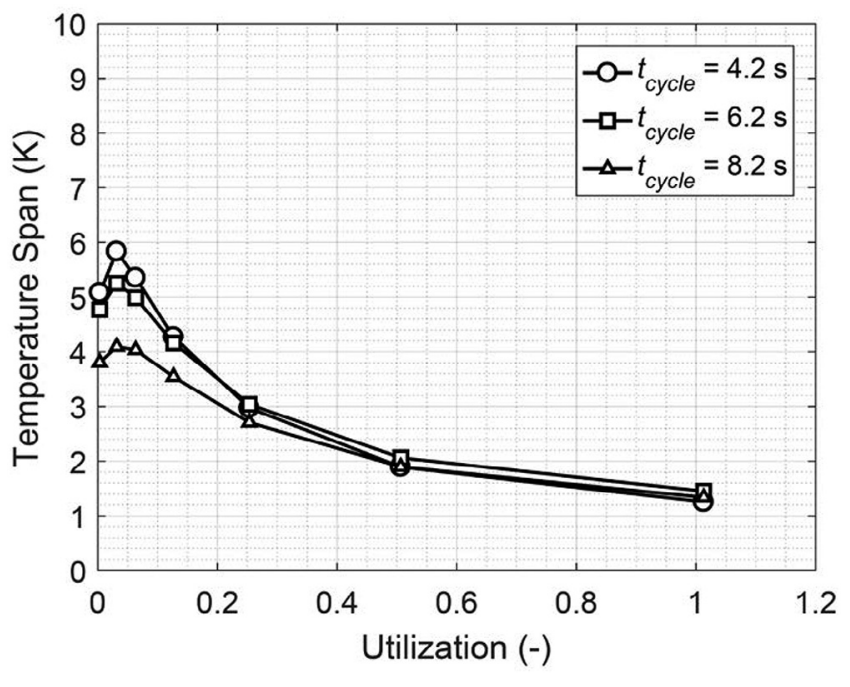

Fig. 7 - Influence of utilization factor and cycle durations on temperature span in unloaded CHEX case.

obtained for the lowest temperature spans. Moreover, reducing the cycle duration shifts the curves and enhances the cooling load. Reducing the cycle duration from $8.2 \mathrm{~s}$ to $4.2 \mathrm{~s}$ doubles the cooling load, nearly from 30 to $60 \mathrm{~W} / \mathrm{m}$, while the temperature span varies in the range of 4.5 and $5.5 \mathrm{~K}$. On the other hand, it is also interesting to note that the curves in Fig. 10 do not smoothly descend. In contrary, at the lowest cooling load the reduction in temperature span suddenly alters the curves backward. One can realize that the reason for this sudden change corresponds to the peak in Fig. 9.

Fig. 11 illustrates the variations of COP regarding the temperature span for different cycle durations. The highest COP values are observed for the lowest temperature spans in each cycle duration. At the small COP values, i.e. less than 0.1 , the influence of cycle duration becomes apparent.

\subsection{Effect of the heat transfer fluid}

In this study, three different heat transfer fluids (HTFs), (i) water, (ii) ethanol-water mixture, and (iii) ethylene glycol are considered. In this set of analyses, the cycle duration is fixed to be $4.2 \mathrm{~s}$. In Fig. 12, the variations of temperature span values are presented for different HTFs. It is clear that, for the current magnetic bed design and the working conditions, there is no significant change observed for the selected fluid types. There is a slight difference for the utilization factor values less than $\varphi=0.0317$. Since the mass flow rate is significantly low at small utilization factors (see Table 1), the effect of thermo-physical properties may become clear.

In Fig. 13, the influence of type of HTF is given regarding to two dimensionless quantities; $\mathrm{COP}$ and utilization factor. Increasing the utilization factor enhances the performance of the cooling unit, and the highest COP values are observed for the maximum utilization factors. Even though there is no significant difference between each type of fluid in terms of the temperature span, when the results are transformed into nondimensional quantities the effect of HTF becomes more apparent, especially for the highest utilization value. For the 


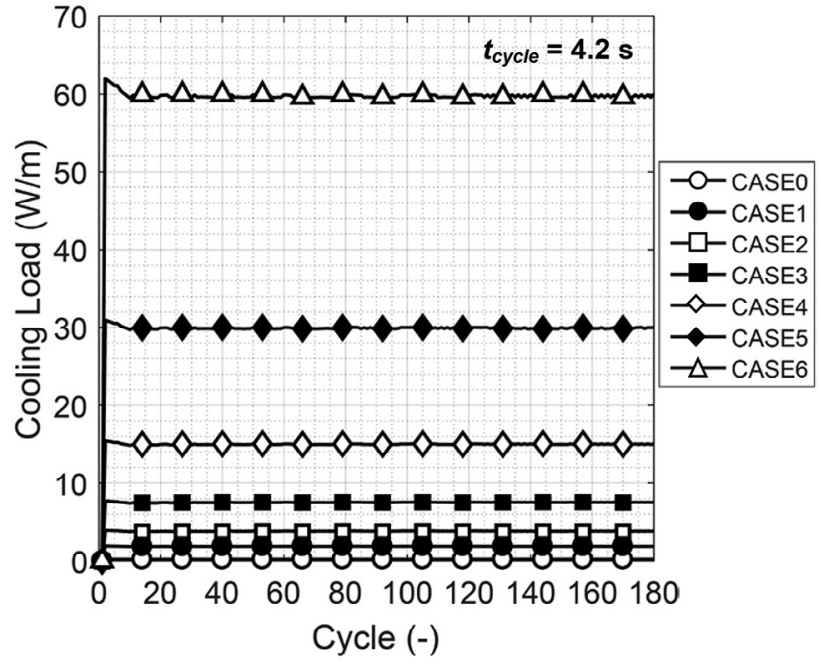

(a) $t_{\text {cycle }}=4.2 \mathrm{~s}$

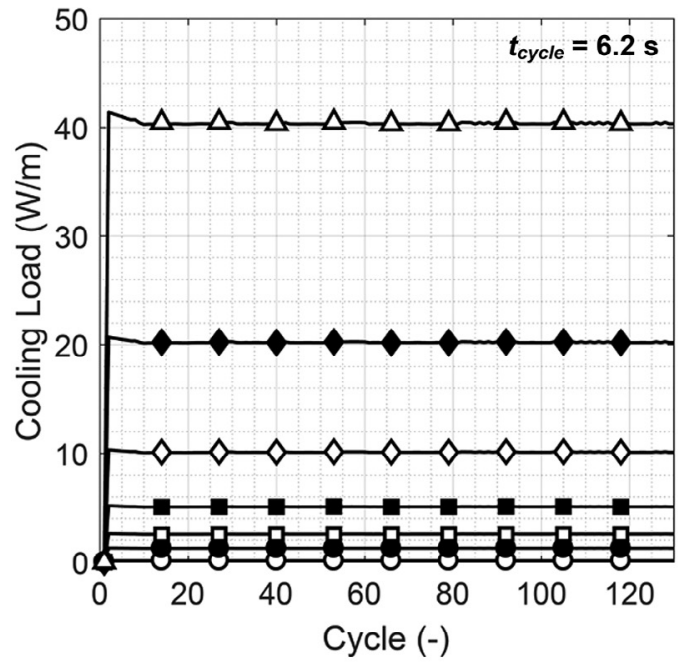

(b) $t_{\text {cycle }}=6.2 \mathrm{~s}$

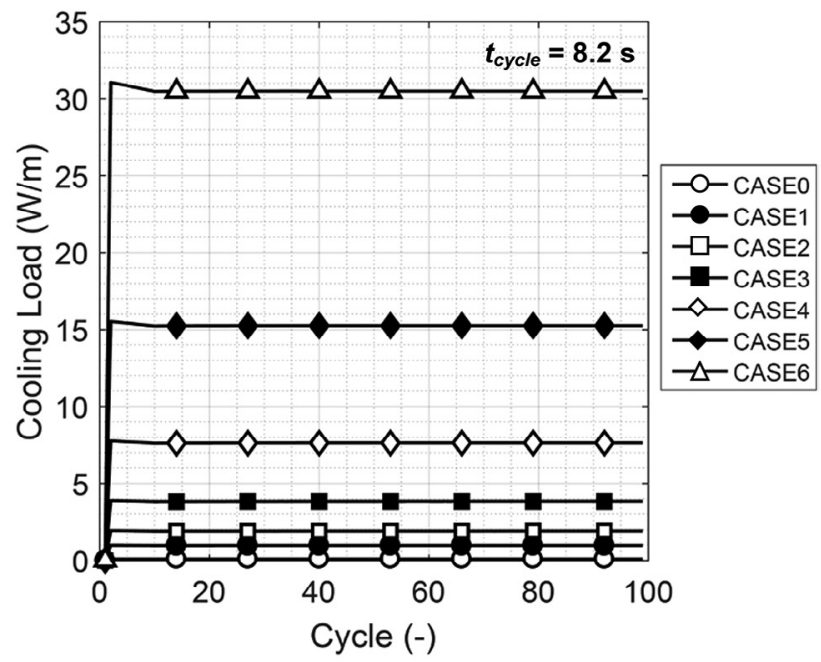

(c) $t_{\text {cycle }}=8.2 \mathrm{~s}$

Fig. 8 - Time evaluation of cooling load for different cycle durations in loaded CHEX case.

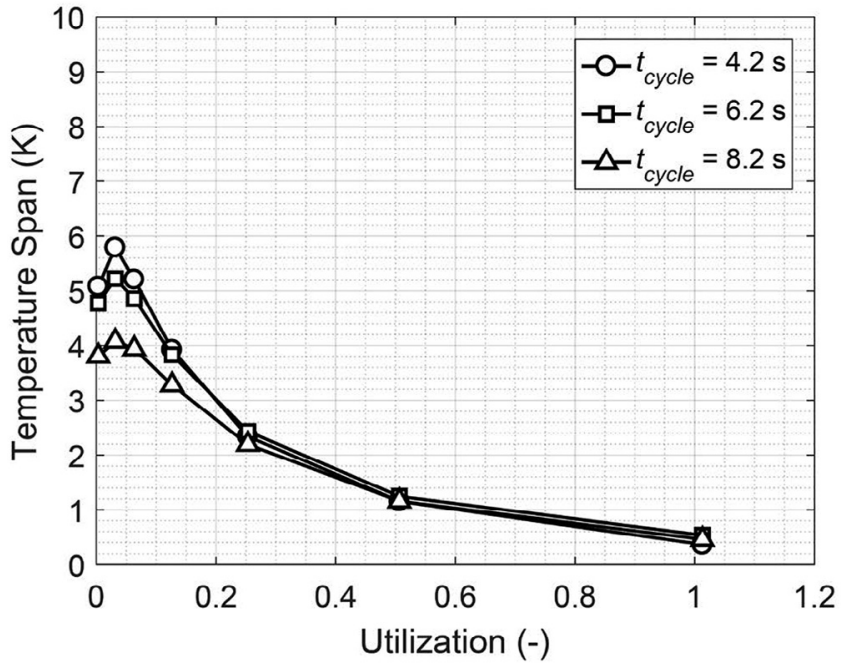

Fig. 9 - Influence of utilization factor $(\varphi)$ and cycle durations on temperature span in loaded CHEX case.

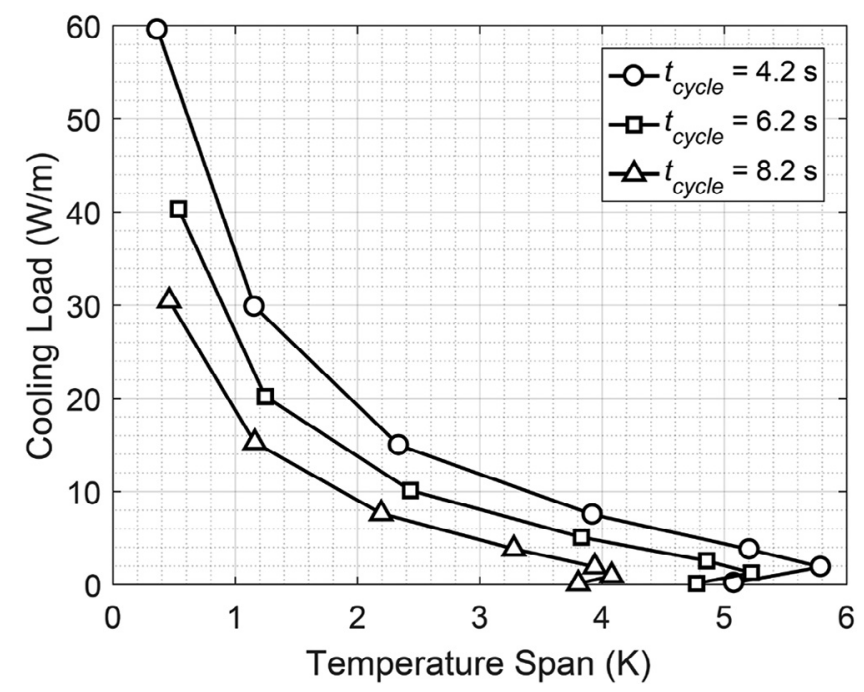

Fig. 10 - Cooling load vs. temperature span in loaded CHEX case for different cycle durations.

current system, the highest COP values are obtained to be 0.7, 0.65 and 0.60 for water, ethylene glycol and ethanol-water mixture, respectively.

\section{Conclusions}

In this study, first, in order to determine the dimension of the magnetic cooling unit depending on air gap size and the magnetic flux density, ANSYS Maxwell analysis is done. Then, the magnetic cooling unit (Gd bed) is numerically simulated in ANSYS-FLUENT CFD solver. The current study is restricted to develop and adapt a numerical scheme in commercial CFD solver. Unlike using a reduced 1D flow field solution as in the previous numerical studies, a 2D flow field is solved coupled with the $2 \mathrm{D}$ heat diffusion inside the Gd plate. This approach 


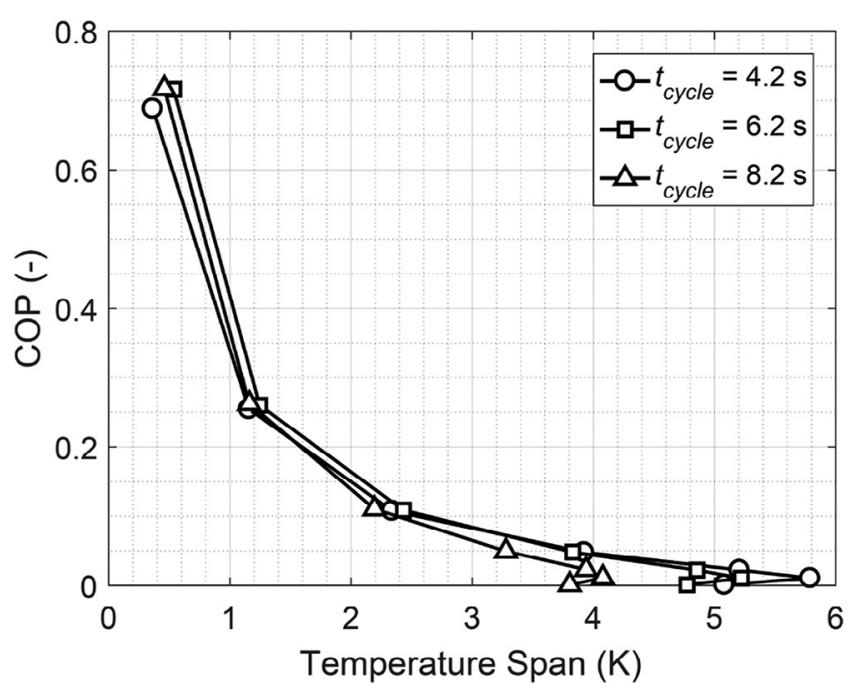

Fig. 11 - COP vs. temperature span in loaded CHEX case for different cycle durations.

provides better predictions and much closer results to the experimental results.

Two different sets of analyses have been conducted by assuming an insulated cold heat exchanger (CHEX) and defining an artificial cooling load in the CHEX. Parametric analyses are conducted to investigate the effect of the velocity of heat transfer fluid (HTF), magnetic field, and types of HTF on the performance of the magnetic cooling system. The performance metrics of the magnetic cooling system are investigated with regards to the temperature span of the magnetic cooling unit and the cooling load. It is concluded that reducing the cycle duration ensures reaching lower temperature values. Similarly, reducing the velocity of the HTF allows reducing the outlet temperature of the HTF. For the current system, the highest temperature spans are obtained numerically as around $6 \mathrm{~K}, 5.2 \mathrm{~K}$ and $4.1 \mathrm{~K}$ for cycle durations of $4.2 \mathrm{~s}, 6.2 \mathrm{~s}$ and $8.2 \mathrm{~s}$, respectively.

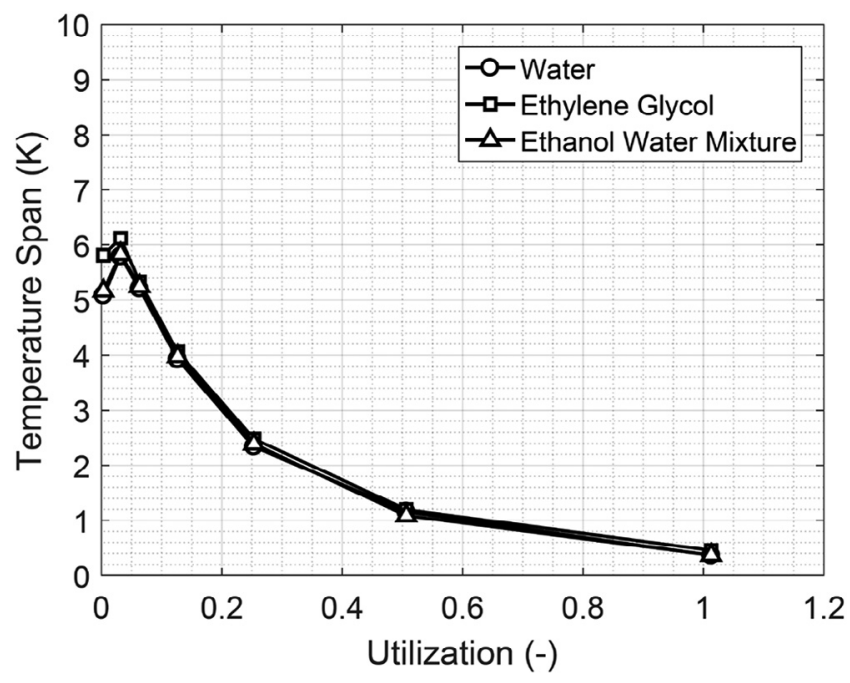

Fig. 12 - Influence of utilization factor and type of fluid on temperature span.

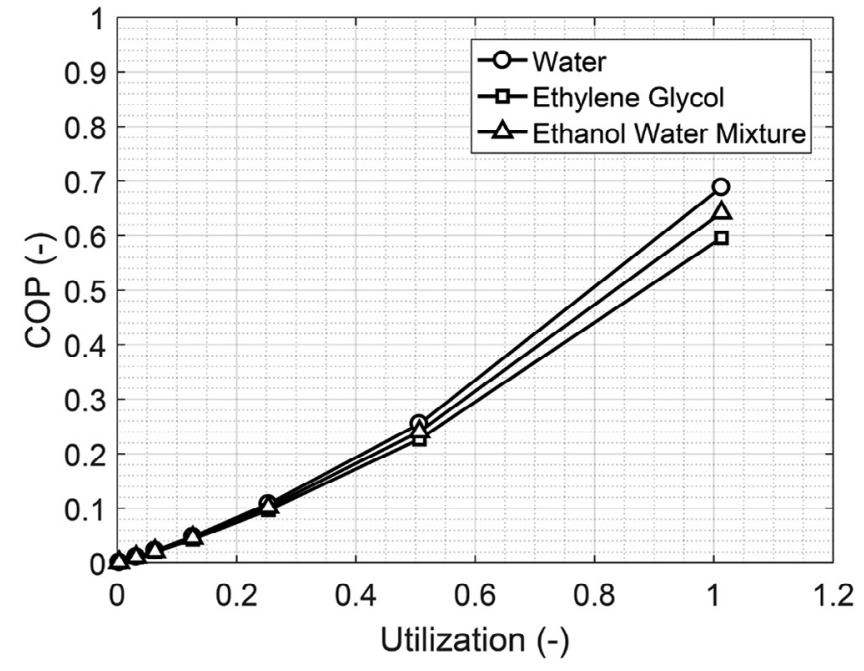

Fig. 13 - Variations of COP with utilization factor for different types of HTFs.

User-defined-functions are implemented into the commercial CFD solver, and the algorithm is tested by reproducing an experimental work from the literature. Three sets of parametric studies have been conducted to introduce the influence of principle operating parameters of the magnetocaloric cooling unit, such as the cycle duration, the type of HTF and the velocity of the HTF. The comparative results indicate that the ethylene-glycol provides lower temperature values at the outlet of the HTF. On the other hand, reducing the cycle duration provides lower temperature values but inversely affects the COP. Besides, the heat transfer phenomena is enhanced for the small velocity values of the HTF, and lower temperature values are obtained at lower velocities. The developed numerical method could be used by the researchers in the field to simulate the magnetic cooling effect in more complex geometries and fluid flow conditions.

\section{Acknowledgments}

The authors would like to thank the Scientific and Technological Research Council of Turkey (TUBITAK) for the financial support given to the project entitled "Experimental Performance Evaluation of a Solar Assisted Magnetic Cooling System (Project no. 114M829)".

\section{Appendix A}

\section{A1. Magnetic field analysis}

In magnetic refrigeration devices, generation of the magnetic field needs electromagnets or permanent magnets. Furthermore, magnet assembly has a crucial importance given that some parameters such as magnetic flux density, the volume of the air gap and the magnets all significantly affect the performance of the overall system. It is considered that magnets must generate high magnetic flux density with a uniform flux, and 


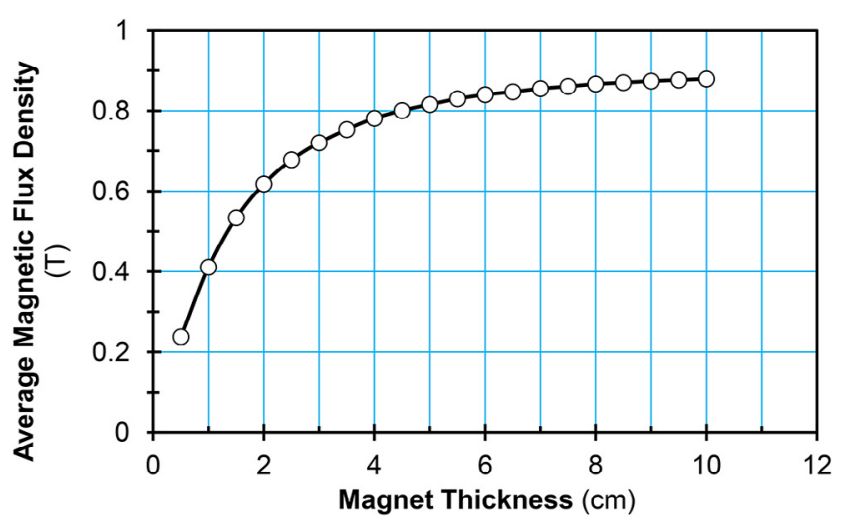

(a)

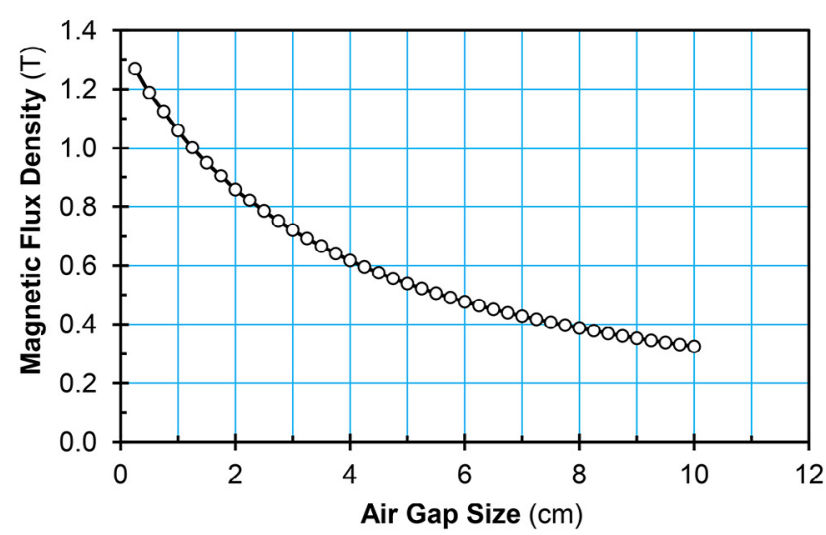

(b)

Fig. A1 - Change of magnetic flux density with air gap and magnet thickness.

the amount of flux leakage must be as low as possible. In addition, the minimum amount of magnets should be used to keep the cost low, and the volume of magneto-caloric material should be as large as possible to increase the heat transfer area.

In this study, NdFeB - N52 type permanent magnets are assumed to be used for magnetic field generation. The magnet properties are taken from the manufacturer (K\&J Magnetics Inc, 2016). Different magnet thicknesses varying from $0.5 \mathrm{~cm}$ to $10 \mathrm{~cm}$ are evaluated by using ANSYS Maxwell software. Air gap is taken $4 \mathrm{~cm}$ because of manufacturing restrictions of magnetic cooling unit (regenerator or Gd bed) for planned experimental study in the future. As a result, the thickness of each magnet is selected as $2 \mathrm{~cm}$ after analysis of the results from ANSYS Maxwell analysis. Fig. A1 shows the change of magnetic flux density with air gap and magnet thickness.

We have used the ANSYS Maxwell library for the magnet properties such as remanence, coercivity, maximum energy product, etc., and their values are given in Table A1. In ANSYS Maxwell analysis, the average magnetic flux density on the Gd plates is calculated to be 0.76 Tesla due to the distribution of the magnetic flux. In conclusion, the final design properties of the magnet assembly are shown in Table A1. The mesh sizing given in the table results from an ANSYS Maxwell analysis where the percent error target is chosen as $1.1 \%$ and the converged energy error percentage is $0.21562 \%$, which are acceptable error bounds for the system considered.
Table A1 - Properties of the magnet assembly resulted

from ANSYS-Maxwell analysis.

Maximum magnetic flux

density on the Gd bed

Average magnetic flux density $\quad 0.76$ Tesla

on the Gd bed

Minimum magnetic flux

density on the Gd bed

Number of the Gd plates

Air gap

One Gd plate dimension

Relative permeability of Gd at

$20^{\circ} \mathrm{C}, 1 \mathrm{~atm}$

Volume of all plates

Yoke type

Magnet type

Remanence (at $20^{\circ} \mathrm{C}$ for N52)*

Coercivity (at $20^{\circ} \mathrm{C}$ for N52)

Maximum energy

product(for N52)*

Mesh

0.98 Tesla

0.27 Tesla

50

$4 \mathrm{~cm}$

$0.1 \mathrm{~cm}(\mathrm{w}) \times 20 \mathrm{~cm}(\mathrm{H}) \times 2.5 \mathrm{~cm}(\mathrm{~W})$

1.48

$0.00025 \mathrm{~m}^{3}$

Steel -1010

NdFeB - N52

$14.6 \mathrm{k}$ Gauss

$-899225.4284 \mathrm{~A} / \mathrm{m}$ (11300 Oe)

52 MGOe

301967 tetrahedral

* These values are taken from ANSYS Maxwell library.

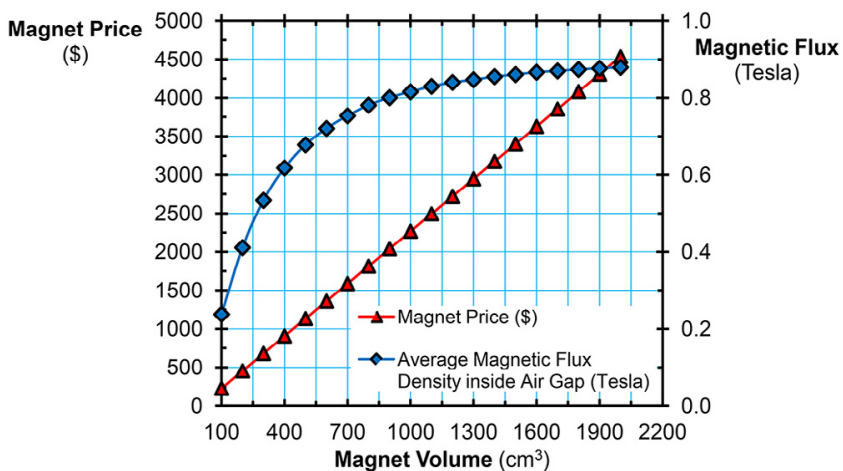

Fig. A2 - Change in magnet cost with magnetic flux density and magnet volume.

Fig. A2 indicates the change of magnet cost with magnetic flux density and magnet volume for the $4 \mathrm{~cm}$ air gap. It is seen from Fig. A2 that if the thickness of the magnet is increased, magnetic flux density does not change effectively at saturation region (above $1000 \mathrm{~cm}^{3}$ ). The current magnet has been selected as $20 \mathrm{~cm}(\mathrm{~L}) \times 2 \mathrm{~cm}(\mathrm{H}) \times 10 \mathrm{~cm}(\mathrm{~W})$, and so its volume is $400 \mathrm{~cm}^{3}$.

\section{Appendix B}

\section{B1. Mean field theory}

Maxwell relations yield the following correlations between the adiabatic temperature and the entropy (Tishin, 1990),

$\left(\frac{\partial T}{\partial B}\right)_{S}=\left(\frac{\partial \Delta T_{a d}}{\partial B}\right)_{S}$

$\Delta T_{a d}=\frac{T}{c(B, T)} S_{\text {total }}(B, T)$. 
The total entropy of a magnetic material consists of three main components: $S_{\text {magnetic }}, S_{\text {lattice, }}$ and $S_{\text {electron. }}$. The electron entropy is commonly disregarded since its effect is quite small compared to the others. Magnetic entropy depends on the temperature and the magnetic flux intensity (Tishin, 1990),

$S_{\text {magnet }}=\frac{R_{u}}{M_{M}}\left\{\ln \left[\sinh \left(\frac{2 J+1}{2 J} X\right)\right]-\ln \left[\sinh \left(\frac{X}{2 J}\right)\right]-X_{J}(X)\right\}$

where $B_{J}(X)$ and $J$ represent Brillouin function and total angular momentum, respectively. $X, B_{J}(X)$, and the magnetic entropy can be evaluated by solving the following equations together with the Eq. (B.3),

$B_{J}(X)=\frac{2 J+1}{2 J} \operatorname{coth}\left(\frac{2 J+1}{2 J} X\right)-\frac{1}{2 J} \operatorname{coth}\left(\frac{X}{2 J}\right)$

$X=\frac{g_{J} \mu_{B} J B}{K T}+\frac{3 T_{\text {curie }} J B_{J}(X)}{T(J+1)}$

where $\mu_{\mathrm{B}}$ is Bohr magneton, $g$ is Spectroscopic splitting factor, $\mathrm{K}$ is the Boltzmann constant, and $\mathrm{T}_{\text {curie }}$ is Curie temperature of the magnetocaloric material. Lattice entropy, on the other hand, is defined as a function of the material temperature,

$S_{\text {lattice }}=\frac{R_{U}}{M_{M}}\left[-3 \ln \left(1-e^{-T_{\text {debye }} / T}\right)+12\left(\frac{T}{T_{\text {debye }}}\right)^{3} \int_{x=0}^{T_{\text {debye }} / T} \frac{x^{3}}{e^{x}-1} d x\right]$.

Specific heat of the magnetocaloric material was derived from the total change in the entropy:

$c(B, T)=T\left(\frac{\partial S}{\partial T}\right)_{B}$

\section{B2. Algorithm of the user defined function}

Fig. B1 illustrates the flow diagrams of Semi-Implicit Method for Pressure Linked Equations (SIMPLE) algorithm and UDF. In the SIMPLE algorithm the momentum, continuity and energy equations are resolved sequentially until the residuals of each governing equations are reduced below a predefined convergence criterion. In each SIMPLE iteration, the CFD solver calls the UDF, and the temperature values of the computational nodes for the solid domain are transferred from solver to the script. At this point, an iterative algorithm executes to compute the specific heat and energy source term $\left(\right.$ mce, $\mathrm{Wm}^{-3}$ ) of each computational node.

Since the lattice entropy depends only on the cell temperature of the Gd, a numerical integration procedure directly computes the first component of the entropy, the lattice, by using Eq. (B6). Magnetic entropy term (Eq. B3), on the other hand, is coupled with Eqs. (B4) and (B5). That is, an iterative shooting algorithm is implemented to resolve the magnetic entropy in a reasonable accuracy. The total entropy of $\mathrm{Gd}$ is then used to evaluate the specific heat value. A higher order (4th order) numerical derivation scheme is utilized in Eq. (B7) to obtain the specific heat of Gd precisely. Later on, the adiabatic temperature change was obtained from Eq. (B2), and as the last step, the mce was computed from the Eqs. (B1) and (7).

In Fig. B2, the variations of the magnetic entropy and change in magnetic entropy are compared with the one that is obtained from the literature (Bouchekara and Nahas, 2012). Here the solid lines represent the evaluated values using the procedure that is described in Appendix B1 and the symbols denote the numerical data from the reference work (Bouchekara and Nahas, 2012). Fig. B2(a) shows the variation of magnetic entropy as a function of the Gd temperature and the magnetic flux density. Here the variations are compared for four different
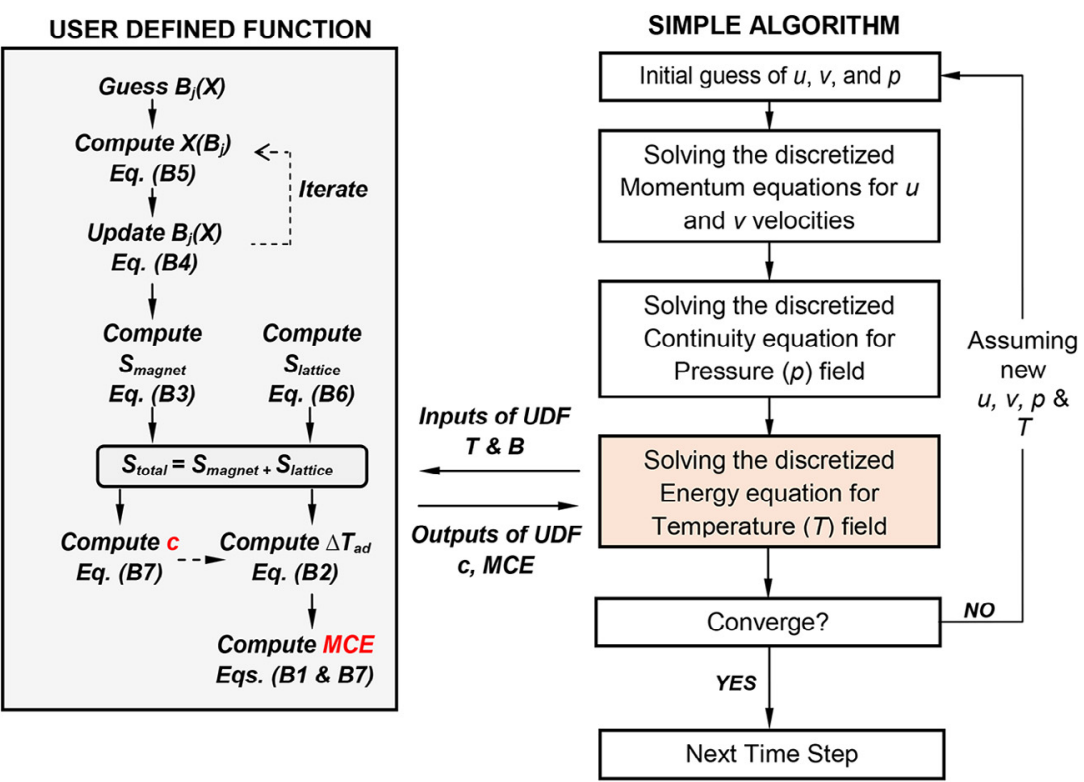

Fig. B1 - Flow diagram of the script. 


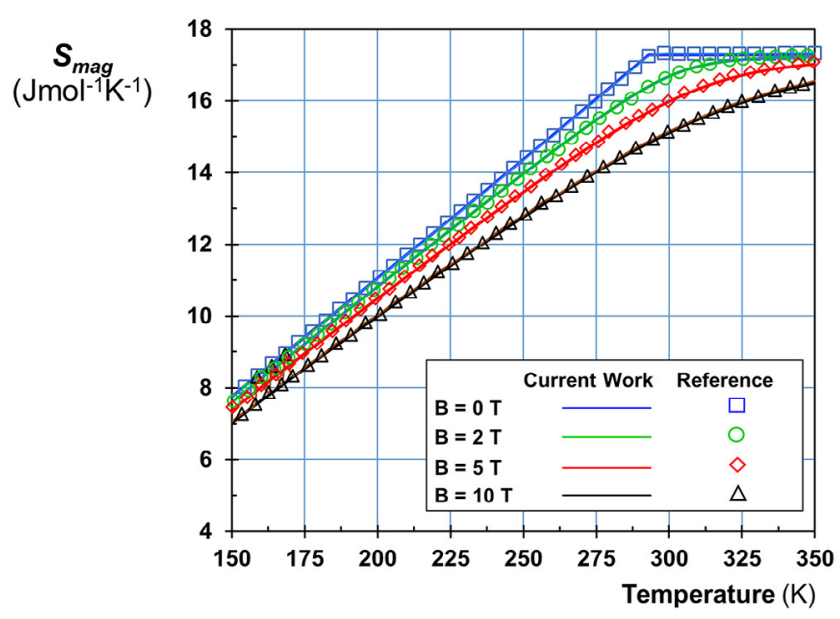

(a) Magnetic entropy

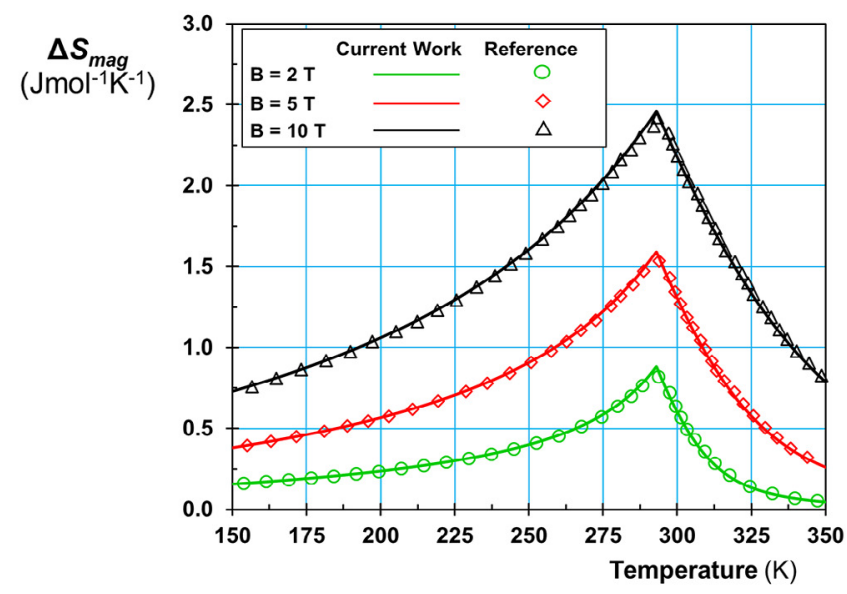

(b) Magnetic entropy variation

Fig. B2 - Comparative results for magnetic entropy and magnetic entropy variation of $\mathrm{Gd}$.

magnetic field intensity values, $B=0.0,2.0,5.0$ and 10.0 Tesla. Under zero magnetic field, there is a sharp change near the Curie temperature of the material. Below $\mathrm{T}_{\text {curie }}$, the variation of the magnetic entropy as a function of temperature is almost linear, while beyond the Curie temperature, the magnetic entropy becomes independent from the temperature. In Fig. B2(b) the variations of the change in magnetic entropy are given as a function of the magnetic flux intensity and the temperature. The entropy change increases as the temperature increases through the Curie temperature, and beyond the Curie temperature the entropy variation tends to reduce significantly. Comparative results suggest that the evaluated data are consistent with the results that are provided in the reference study.

\section{REFERENCES}

Almeida, A.T., Fonseca, P., Falkner, H., Bertoldi, P., 2003. Market transformation of energy-efficient motor technologies in the EU. Energy Policy 31 (6), 563-575.

Aprea, C., Cardillo, G., Greco, A., Maiorino, A., Masselli, C., 2015 a. A comparison between experimental and 2D numerical results of a packed-bed active magnetic regenerator. Appl. Therm. Eng. 90, 376-383.

Aprea, C., Greco, A., Maiorino, A., 2015b. GeoThermag: a geothermal magnetic refrigerator. Int. J. Refrigeration 59, 1424-1435.

Aprea, C., Greco, A., Maiorino, A., Masselli, C., 2016. The energy performances of a rotary permanent magnet magnetic refrigerator. Int. J. Refrigeration 61, 1-11.

Bahl, C.R.H., Petersen, T.F., Pryds, N., Smith, A., 2008. A versatile magnetic refrigeration test device. Rev. Sci. Instrum. 79 (9), 093906-1-7.

Bhutta, M.M.A., Hayat, N., Bashir, M.H., Khan, A.R., Ahmad, K.N., Khan, S., 2012. CFD applications in various heat exchangers design: a review. Appl. Therm. Eng. 32, 1-12.

Bjørk, R., Bahl, C.R.H., Katter, M., 2010. Magnetocaloric properties of LaFe13-x-yCoxSiy and commercial grade Gd. Magn. Magn. Mater. 322, 3882-3888.

Bouchekara, H.R.E.H., Nahas, M., 2012. Magnetic refrigeration technology at room temperature. INTECH Open Access Publisher.

Brown, G.V., 1976. Magnetic heat pumping near room temperature. J. Appl. Phys. 47, 3673-3680.

Chen, Y.C., Qin, L., Meng, Z.S., Yang, D.F., Wu, C., Fu, Z., et al., 2014. Study of a magnetic-cooling material $\mathrm{Gd}(\mathrm{OH}) \mathrm{CO} 3$. J. Mater. Chem. A 2 (25), 9851.

Coulomb, D., 2007. The IIR and environmental challenges facing the refrigeration sector. In: Poredos, A., Sarlah, A. (Eds.), Proceedings of the Second International Conference on Magnetic Refrigeration at Room Temperature. April 11-13 Portoroz, Slovenia. International Institute of Refrigeration, Paris, pp. 3-5.

De Oliveira, N.A., von Ranke, P.J., 2010. Theoretical aspects of the magnetocaloric effect. Phys. Rep. 489 (4-5), 89-159.

Ekren, O., Ezan, M.A., Erek, A., 2011. Experimental assessment of energy storage via variable speed compressor. Int. J. Refrigeration 34, 1424-1435.

Engelbrecht, K.L., Nellis, G.F., Klein, S.A., 2005. A numerical model of an active magnetic regenerator refrigeration system, Cryocoolers 13, Springer US, Online ISBN: 978-0-387-27533-8, 471-480.

Eriksen, D., Engelbrecht, K., Bahl, C.R.H., Bjørk, R., Nielsen, K.K., Insinga, A.R., et al., 2015. Design and experimental tests of a rotary active magnetic regenerator prototype. Int. J. Refrigeration 58, 14-21.

Giauque, W.F., MacDougall, D.P., 1933. Attainment of temperatures below $1 \mathrm{~K}$ absolute by demagnetization of Gd2(SO4)3.8H2O. Phys. Rev. Lett. 43 (9), 768.

Goetzler, W., Guernsey, M., Young, J., Fuhrman, J., Abdul-Aziz, O., 2016. The future of air conditioning for buildings, U.S. Department of Energy, Office of Energy Efficiency and Renewable Energy Building Technologies Office report, http://eere.energy.gov/buildings. (Accessed September 2016).

Kamran, M.S., Sun, J., Tang, Y.B., Chen, Y.G., Wu, J.H., Wang, H.S., 2016. Numerical investigation of room temperature magnetic refrigerator using microchannel regenerators. Appl. Therm. Eng. 102, 1126-1140.

Kawanami, T., Hirano, S., Fumoto, K., Hirasawa, S., 2011. Evaluation of fundamental performance on magnetocaloric cooling with active magnetic regenerator. Appl. Therm. Eng. 31 (6), 1176-1183.

Kitanovski, A., Plaznik, U., Tušek, J., Poredoš, A., 2014. New thermodynamic cycles for magnetic refrigeration. Int. J. Refrigeration 37, 28-35.

Kitanovski, A., Tušek, J., Tomc, U., Plaznik, U., Ozbolt, M., Poredoš, A., 2015. Magnetocaloric energy conversion from theory to applications. In: Green Energy and Technology. Springer, Switzerland. ISSN: 1865-3529. 
K\&J Magnetics Inc., 2016. Neodymium magnet physical properties, http://www.kjmagnetics.com. (Accessed April 2016).

Kusiak, A., Li, M., Fan, T., 2010. Modeling and optimization of HVAC energy consumption. Appl. Energy 87, 3092-3102.

Lionte, S., Vasile, C., Siroux, M., 2015. Numerical analysis of a reciprocating active magnetic regenerator. Appl. Therm. Eng. 75, 871-879.

Lozano, J.A., Capovilla, M.S., Trevizoli, P.V., Engelbrecht, K., Bahl, C.R., Barbosa, J.R., 2016. Development of a novel rotary magnetic refrigerator. Int. J. Refrigeration 68, 187197.

Mota-Babiloni, A., Navarro-Esbrí, J., Barragán-Cervera, A., Molés, F., Peris, B., 2015. Analysis based on EU Regulation No 517/ 2014 of new HFC/HFO mixtures as alternatives of high GWP refrigerants in refrigeration and HVAC systems. Int. J. Refrigeration 52, 21-31.

Nielsen, K.K., Bahl, C.R.H., Smith, A., Bjørk, R., Pryds, N., Hattel, J., 2009. Detailed numerical modeling of a linear parallel-plate active magnetic regenerator. Int. J. Refrigeration 32 (6), 14781486.

Ožbolt, M., Kitanovski, A., Tušek, J., Poredoš, A., 2014. Electrocaloric vs. magnetocaloric energy conversion. Int. J. Refrigeration 37, 16-27.

Petersen, T.F., Engelbrecht, K., Bahl, C.R.H., Elmegaard, B., Pryds, N., Smith, A., 2008a. Comparison between a 1D and a 2D numerical model of an active magnetic regenerative refrigerator. J. Phys. D Appl. Phys. 41 (10), 105002.

Petersen, T.F., Pryds, N., Smith, A., Hattel, J., Schmidt, H., Høgaard, K.H.J., 2008b. Two-dimensional mathematical model of a reciprocating room-temperature Active Magnetic Regenerator. Int. J. Refrigeration 31 (3), 432-443.

Plaznik, U., Tušek, J., Kitanovski, A., Poredoš, A., 2013. Numerical and experimental analyses of different magnetic thermodynamic cycles with an active magnetic regenerator. Int. J. Refrigeration 59 (1-2), 52-59.
Qian, S., Geng, Y., Wang, Y., Ling, J., Hwang, Y., Radermacher, R., et al., 2016. A review of elastocaloric cooling: materials, cycles and system integrations. Int. J. Refrigeration 64 (1), 1-19.

Roudaut, J., Kedous-Lebouc, A., Yonnet, J.P., Muller, C., 2011. Numerical analysis of an active magnetic regenerator. Int. J. Refrigeration 34 (8), 1797-1804.

Sarlah, A., Poredos, A., 2010. Dimensionless numerical model for simulation of active magnetic regenerator refrigerator. Int. J. Refrigeration 33 (6), 1061-1067.

Sarlah, A., Kitanovski, A., Poredos, A., Egolf, P.W., Sari, O., Gendre, F., et al., 2006. Static and rotating active magnetic regenerators with porous heat exchangers for magnetic cooling. Int. J. Refrigeration 29 (8), 1332-1339.

Siddikov, B.M., Wade, B.A., Schultz, D.H., 2005. Numerical simulation of the active magnetic regenerator. Comput. Math. Appl. 49, 1525-1538.

Smith, A., 2013. Who discovered the magnetocaloric effect? Warburg, Weiss and the connection between magnetism and heat. Eur. Phys. J. H 38 (4), 507-517.

Tishin, A.M., 1990. Magnetocaloric effect in strong magnetic fields. Cryogenics 30 (2), 127-136.

Weiss, P., Piccard, A., 1918.

Surunnouveauphe'nome'enemagne'tocalorique. Compt. Rend. Acad. Sci. 166-352.

You, Y., Yu, S., Tian, Y., Luo, X., Huang, S., 2016. A numerical study on the unsteady heat transfer in active regenerator with multi-layer refrigerants of rotary magnetic refrigerator near room temperature. Int. J. Refrigeration 65, 238-249.

Yu, B.F., Gao, Q., Zhang, B., Meng, X.Z., Chen, Z., 2003. Review on research of room temperature magnetic refrigeration. Int. J. Refrigeration 26, 622-636.

Zimm, C., Jastrab, A., Sternberg, A., Pecharsky, V.K., Gschneidner, K.A., Jr., Osborne, M., et al., 1998. Description and performance of a near-room temperature magnetic refrigerator. Adv. Cryog. Eng. 43, 1759-1766. 